\title{
Potential-dependent competitive processes on platinum in acid solution in the presence of propargyl alcohol
}

\author{
M.C. Arévalo, E. Pastor, S. González and A. Arévalo \\ Departamento de Quimica Fisica, Universidad de La Laguna, La Laguna, Tenerife (Spain) \\ M.C. Giordano * and A.J. Arvia \\ INIFTA, Universidad Nacional de La Plata, La Plata (Argentina)
}

(Received 25 July 1989; in revised form 16 October 1989)

\begin{abstract}
The electroadsorption interactions between dilute propargyl alcohol and smooth platinum in $0.5 \mathrm{M}$ $\mathrm{H}_{2} \mathrm{SO}_{4}$ at $25^{\circ} \mathrm{C}$ have been investigated at different potentials. When the platinum electrode is covered by $\mathrm{H}$ atoms the hydrogenation of propargyl alcohol takes place. Otherwise, when the platinum electrode is held at a potential located in the double-layer region, the electroadsorption of propargyl alcohol involves a disnuptive electro-oxidation yielding strongly bound adsorbed residues. The latter can be electrodesorbed presumably as carbon dioxide and protons. This process occurs within the O-electroadsorption potential range. The complete residue electrodesorption requires several voltammetric cycles. Competition between the hydrogenation reaction and the disruptive electroadsorption process can be observed at potentials where the platinum surface is partially covered by $\mathrm{H}$ atoms.
\end{abstract}

\section{(I) INTRODUCTION}

The electrochemistry of propargyl alcohol (PA) was first studied in relation to the inhibition of iron corrosion [1]. The inhibiting properties of PA can be explained, in part, through the direct interaction of the triple bond of PA with the metal surface and also through the production of adsorbates which are able to react at the metal surfaces yielding polymeric species which modify the characteristics of the metal/ solution interface [2]. On the other hand, PA can be electro-oxidized on smooth Pt, yielding mainly $\mathrm{CO}_{2}$, and on platinized $\mathrm{Pt}$, forming several other products in addition to $\mathrm{CO}_{2}$ [3]. These reactions are of interest from the standpoint of the electrochemical combustion of organic fuels and, eventually, of electrochemical

\footnotetext{
$\overline{\star \text { Deceased. }}$
} 
synthesis. In all these cases, the interactions between PA and the metal electrode surface should play a relevant role in the course of the electrochemical processes. Certainly, this fundamental aspect related to the electro-oxidation of PA deserves further investigation under appropriate conditions.

Previous work on the electro-oxidation of $\mathrm{PA}$ on smooth $\mathrm{Pt}$ in $0.5 \mathrm{M} \mathrm{H}_{2} \mathrm{SO}_{4}$ [4], in the range $20-80^{\circ} \mathrm{C}$, concluded that the adsorption process involved in the overall reaction was non-dissociative since no transient current could be observed at the adsorption potential. This result contrasts with the adsorption processes occurring on Pt with other alcohols such as propanol isomers [5,6], in which the dehydrogenation of the molecules takes place, and also with the fact that the electro-oxidation decreases in the order methanol $>$ primary alcohol $>$ secondary alcohol $>t$-alcohol [5]. The electroadsorption of these molecules is favoured by the presence of $\mathrm{H}$ atoms at the $\alpha$-carbon atom positions [5].

At this stage it is of interest to investigate the behaviour of PA, a molecule containing very distinctive reacting groups, on different metal electrodes, paying special attention to the type of interaction between PA and the electrode material at different potentials. This paper is devoted particularly to the interaction of PA with smooth Pt electrode surfaces in acid solution, as this metal, in the absence of PA, exhibits only the $\mathrm{H}$ - and $\mathrm{O}$-electroadsorption processes in definite potential ranges without any appreciable metal corrosion [7].

\section{(II) EXPERIMENTAL}

Runs were made in a conventional Pyrex glass electrochemical cell. The $\mathrm{Pt}$ working electrodes were small spheres of $0.03-0.05 \mathrm{~cm}^{2}$ apparent area. They were prepared by melting the end of a $0.5 \mathrm{~mm}$ diameter wire in an oxygen + gas torch flame followed by quenching in water. The working electrode was later subjected to voltammetric cycling at $0.2 \mathrm{~V} \mathrm{~s}^{-1}$ in $0.5 \mathrm{M} \mathrm{H}_{2} \mathrm{SO}_{4}$ between -0.230 and $1.300 \mathrm{~V}$ (vs. SCE) at $25^{\circ} \mathrm{C}$, until a stabilized $\mathrm{H}$-atom electrosorption voltammogram for a poly-faceted single-crystal $\mathrm{Pt}$ electrode in the acid solution was obtained [8]. The counter-electrode was a large Pt cylindrical grid surrounding the working electrode. The potential applied to the working electrode was measured against a properly shielded saturated calomel electrodc (SCE), which was connected to the rest of the circuit as usual. The electrolyte solution was $0.5 \mathrm{M} \mathrm{H}_{2} \mathrm{SO}_{4}$, which was prepared from $98 \% \mathrm{H}_{2} \mathrm{SO}_{4}$ (Merck p.a.) and Millipore-Milli- $\mathrm{Q}^{\mathrm{R}}$ water. Propargyl alcohol (Merck "zur Synthese") was distilled twice and kept at a low temperature in the dark to minimize any possible decomposition reaction. The purity of PA was verified by gas chromatography and NMR. The PA concentration in solution was varied from $2 \times 10^{-5}$ to $10^{-4} \mathrm{M}$ by adding small portions of $10^{-2} \mathrm{M}$ PA stock solution. The latter was always kept in the dark at about $4^{\circ} \mathrm{C}$. Experiments were performed at $25^{\circ} \mathrm{C}$ with $50 \mathrm{~cm}^{3}$ of electrolyte solution kept continuously under an Ar atmosphere.

A set-up consisting of a PAR 173 potentiostat, a PAR 179 automatic digital coulometer, a PAR 175 Universal programmer, a 3091 Nicolet digital oscilloscope 
and a Hewlett-Packard X-Y recorder was employed for the combined voltammetric and current transient techniques used in the present work.

(III) RESULTS

\section{(III.1) The electroadsorption of propargyl alcohol on smooth platinum}

Taking into account that clean $\mathrm{Pt}$ surface conditions in $0.5 \mathrm{M} \mathrm{H}_{2} \mathrm{SO}_{4}$, i.e. within the so-called double-layer region, are restricted to a small potential window centred at about $0.200 \mathrm{~V}$, these experiments were performed in the following way (Fig. 1a). Once the initial (blank) voltammogram had been recorded (Fig. 1b) in the absence of PA in solution, the potential was first stepped to $1.300 \mathrm{~V}$ to produce nearly a monolayer of $O$ adatoms, and subsequently the potential was stepped to $E_{\mathrm{ad}}=0.200$ $V$. At this potential the corresponding current transient was recorded to ensure that the electroreduction of the $\mathrm{O}$-adatom layer had been completed. Then by keeping the potential fixed at $E_{\mathrm{ad}}=0.200 \mathrm{~V}$ and the current recorder switched on, $0.05 \mathrm{~cm}^{3}$ of $10^{-2} \mathrm{M}$ PA was added to the solution very close to the working electrode region. Under these circumstances an anodic current transient could be observed immediately (Fig. 1c), the charge density involved being about $50 \mu \mathrm{C} \mathrm{cm}^{-2}$. This current jump was taken as evidence of an anodic electroadsorption process related to PA at $E_{\text {ad }}$. It should be noted that the electro-oxidation voltammogram of the adsorption residue run immediately afterwards (Fig. 1d) exhibits a current peak at ca. $1.0 \mathrm{~V}$, i.e. at a potential located within the O-electroadsorption potential range. Likewise, in the same voltammogram one observes strong inhibition of the $\mathrm{H}$-atom electroadsorption-electrodesorption reactions. Furthermore, from the repetitive voltammograms one can also conclude that several oxidation cycles are required to eliminate the adsorbed residue completely. This fact can be followed through the trend of the electrode to recover, although rather slowly, its activity for the HER. The inhibiting effect of the electroadsorbed residue appears to be stronger for the $\mathrm{H}$-atom than for the $\mathrm{O}$-atom reactions. One should also note that the repetitive potential cycles require that the anodic current recorded from $E_{\text {ad }}$ upwards commence at lower potentials. This effect is, in part, due to the re-adsorption of PA, although in this case the formation of other more reactive adsorbates cannot be discarded a priori.

\section{(III.2) Reaction of propargyl alcohol with adsorbed $H$ atoms}

To distinguish the occurrence of a possible reaction between PA and $\mathrm{H}$ atoms, the $\mathrm{Pt}$ electrode was first pretreated in $0.5 \mathrm{M} \mathrm{H}_{2} \mathrm{SO}_{4}$ prior to the addition of PA to the solution (Fig. 2a) in a way which resembles that described in Fig. 2a, except that in this case the potential $E_{\text {ad }}$ was held at a value where the Pt electrode was nearly fully covered by $\mathrm{H}$-atoms, i.e. at the potential boundary related to the incipient HER. In this case, PA was added just when the coverage by $\mathrm{H}$ atoms had reached a constant and stable value. Then a large cathodic, relatively slowly decaying, current 

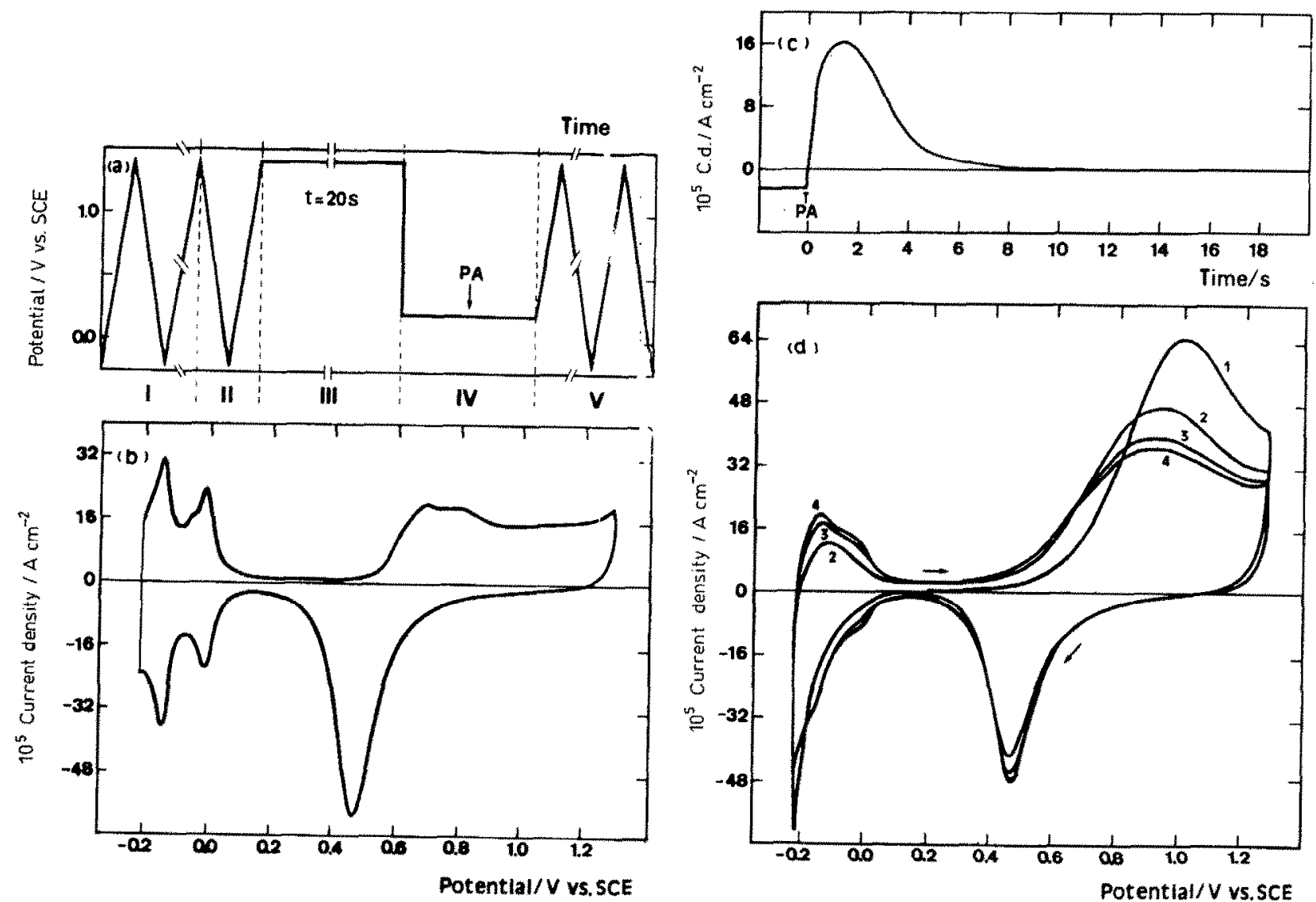

Fig. 1. (a) Combined potential perturbation programme consisting in the following operations: (I) Repetitive triangular potential scanning (pretreatment) at $0.2 \mathrm{~V} \mathrm{~s}^{-1}$; (II) initial voltammogram at $0.2 \mathrm{~V} \mathrm{~s}^{-1}$ (single triangular potential sweep); (III) O-electroadsorption at a constant potential (monolayer level); (IV) O-electroadesorption at a constant potential followed by PA electroadsorption, the current transient being recorded continuously. The arrow indicates the instant at which the O-electroadsorption is finished and PA is added; (V) final voltammetric electro-oxidation of PA electroadsorbed residues. (b) Initial voltammogram run in region I. $0.5 \mathrm{M} \mathrm{H}_{2} \mathrm{SO}_{4} ; 25^{\circ} \mathrm{C}$ (blank). (c) Current transient at $E_{\text {ad }}=0.200 \mathrm{~V}$. PA is added at $t=0$ (see arrow). (d) Repetitive voltammograms obtained at $0.2 \mathrm{~V} \mathrm{~s}^{-1}$ in region $\mathrm{V}$ without correction for PA re-adsorption. The arrows indicate the direction of the voltammetric sweeps and the numbers denote the succesive potential sweeps. 

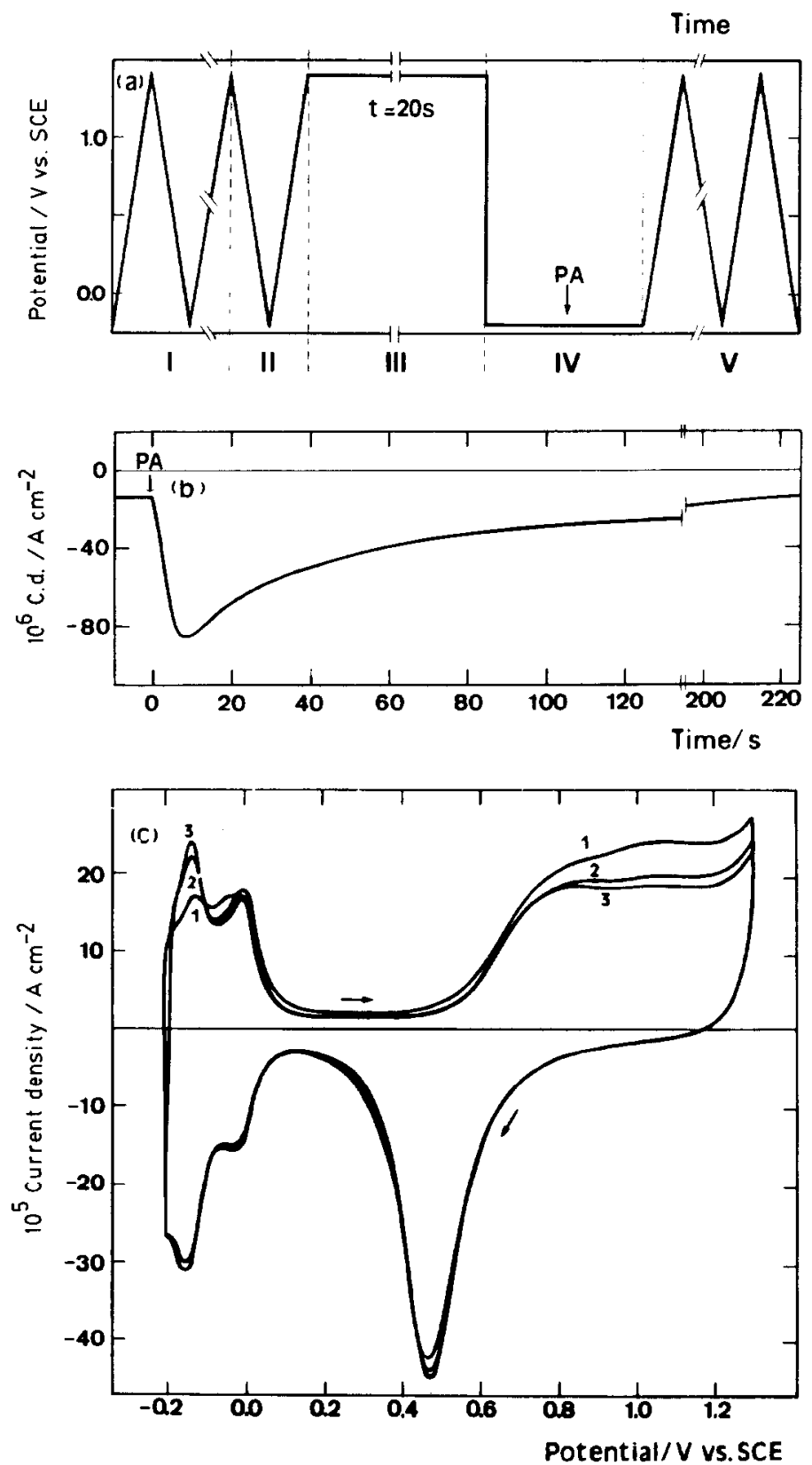

Fig. 2. (a) Combined potential perturbation programme. For its description see Fig. 1a. (b) Current transient at $E_{\text {ad }}=-0.220 \mathrm{~V}$. PA is added at $t=0$ (see arrow). (c) Repetitive voltammograms obtained at $0.2 \mathrm{~V} \mathrm{~s}^{-1}$ in region $\mathrm{V}$ without correction for PA re-adsorption. The arrows indicate the direction of the voltammetric sweep and the numbers denote the successive potential sweeps. 
Time
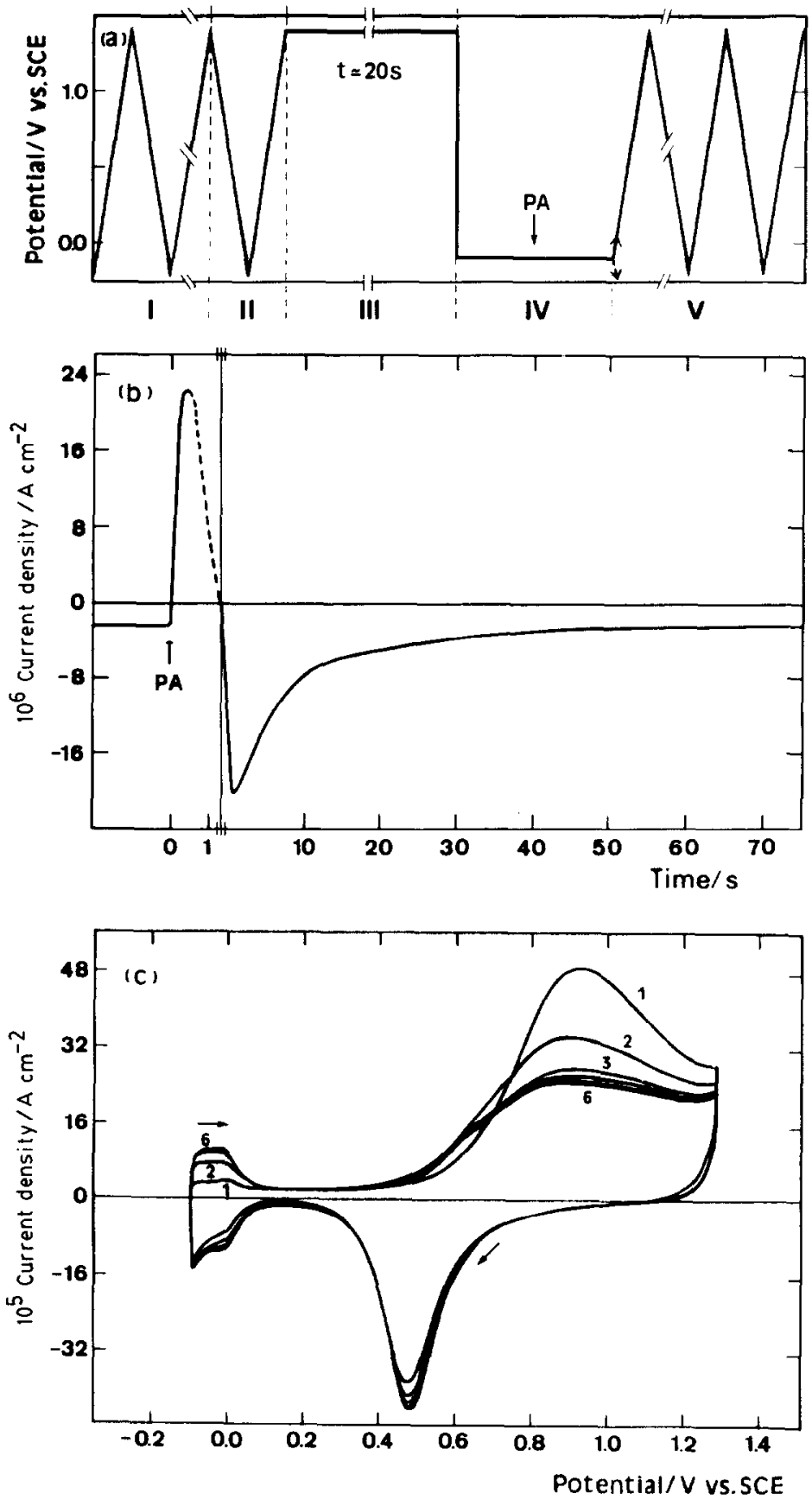


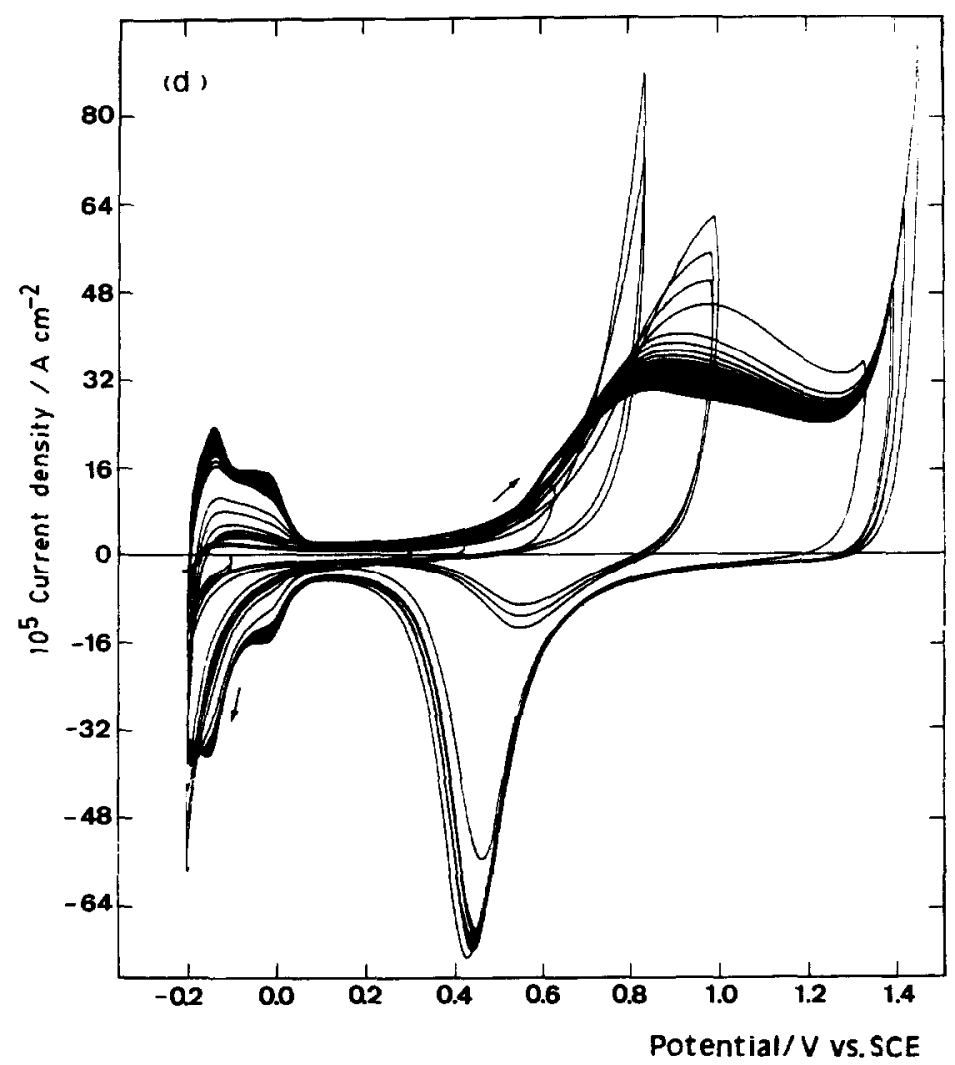

Fig. 3. (a) Combined potential perturbation programme. For a description see Fig. 1a, except that in this case the final voltammetric sweep in region $V$ was started either in the positive (full trace) or in the negative (dashed trace) potential direction. (b) Current transient recorded at $E_{\mathrm{ad}}=-0.100 \mathrm{~V}$. The shape of the anodic current transient (dashed trace) depends on mixing, but the corresponding charge is independent of it. (c) Repetitive voltammograms obtained at $0.2 \mathrm{~V} \mathrm{~s}^{-1}$ in region $\mathrm{V}$ from -0.1 to $1.3 \mathrm{~V}$. (d) Repetitive voltammograms obtained at $0.2 \mathrm{~V} \mathrm{~s}^{-1}$ in region $\mathrm{V}$ covering from $-0.230 \mathrm{~V}$ to different stepwise changed upper switching potentials. The potential sweep was initiated from $-0.100 \mathrm{~V}$ downwards.

transient (Fig. 2b) appeared immediately after the addition of PA. The charge density derived from this current transient, which is about $4700 \mu \mathrm{C} \mathrm{cm}^{-2}$, exceeds by far the value that would be expected for a reaction at the monolayer level, but it can be explained in terms of a reaction between PA and $\mathrm{H}$ adatoms. Once the current transient has reached the baseline, the voltammogram run immediately afterwards from $-0.230 \mathrm{~V}$ upwards (Fig. 2c) shows only a slight inhibition for the $\mathrm{H}$-adatom reaction as well as a slight increase in the O-electroadsorption charge. The latter is probably due to slight adsorption of PA occurring during the positive potential scan. The subsequent triangular potential sweep recovers practically to the voltammetric profile depicted for the blank (Fig. 1b). 


\section{(III.3) Competitive electroadsorption}

The different electroadsorption behaviour of PA on bare $\mathrm{Pt}$ and on $\mathrm{H}$-atom covered Pt electrodes suggests the possibility that the electroadsorption of PA competes with the proper reaction between $\mathrm{H}$ atoms and PA. To demonstrate that this type of process actually takes place, runs were also carried out by starting with a Pt electrode which was only partially covered by $\mathrm{H}$ adatoms (Fig. $3 \mathrm{a}$ ). For this purpose the pretreated Pt electrode was held at $E_{\text {ad }}=-0.100 \mathrm{~V}$, i.e. to a potential at which about half of the electrode surface was covered by $\mathbf{H}$ adatoms, principally strongly bound $\mathrm{H}$ atoms. In this case, the addition of PA immediately produces an anodic current jump which lasts only a short time, about $1 \mathrm{~s}$ (Fig. 3b), and afterwards the current becomes cathodic and decays to nearly zero in about $100 \mathrm{~s}$. The anodic current jump can be explained in terms of the electroadsorption of PA on the bare Pt sites through a process which resembles that already described in Section (III.2). The charge density involved in the anodic portion of the current transient is about $25 \mu \mathrm{C} \mathrm{cm}^{-2}$, approximately half the charge density value derived from the experiment described in Section (III.2) (Fig. 2b). Conversely, the charge density evaluated from the cathodic portion of the current transient is much larger, i.e. about $480 \mu \mathrm{C} \mathrm{cm}^{-2}$. This value can be assigned to the charge required to restore the $\mathrm{H}$-adatom coverage at the $\mathrm{Pt}$ surface, i.e. the $\mathrm{H}$-adatoms consumed through the PA hydrogenation reaction. On the other hand, the time ratio derived from the current transient for the anodic and cathodic processes indicates that after prolonged potential holding at $E_{\mathrm{ad}}=-0.100 \mathrm{~V}$, the electrode surface becomes mostly covered by PA electroadsorbed residues. This conclusion is confirmed throughout the voltammogram run immediately afterwards (Figs. $3 \mathrm{c}$ and $3 \mathrm{~d}$ ) from $-0.100 \mathrm{~V}$ upwards. The voltammogram depicted in Fig. $3 \mathrm{c}$ is, in principle, comparable to that depicted in Fig. 1d. The inhibition of the $\mathrm{H}$-adatom reactions gradually disappears on potential cycling between $-0.230 \mathrm{~V}$ and a stepwise changed upper switching potential. The corresponding voltammograms (Fig. 3d) show gradual oxidation of the adsorbed residue, and, consequently, progressive reactivation of the $\mathrm{Pt}$ electrode for both the $\mathrm{H}$ - and the $\mathrm{O}$-atom electroadsorption processes.

\section{(IV) DISCUSSION}

The electro-oxidation of PA yielding $\mathrm{CO}_{2}$ and protons through a $100 \%$ reaction efficiency would occur according to the following reaction:

$\mathrm{CH} \equiv \mathrm{C}-\mathrm{CH}_{2} \mathrm{OH}+5 \mathrm{H}_{2} \mathrm{O}=3 \mathrm{CO}_{2}+14 \mathrm{H}^{+}+14 \mathrm{e}^{-}$

According to the foregoing results, reaction (1) should be considered as a complex reaction, as has been found for the electro-oxidation of other fuels of much simpler structures [9], as both the formation of electroadsorbates from PA on the smooth Pt surface and a chemical reaction between PA and $\mathrm{H}$ atoms have been demonstrated. Therefore, in order to describe in detail the proper PA electro-oxidation mechanism, 
it is reasonable to consider firstly the different adsorption processes involving PA and the Pt electrode surface.

The PA molecule has three types of preferential reaction site, namely, the acetylenic bond, the $\mathrm{H}$ atoms on the $\alpha$-carbon atom and the alcoholic group. Hence, in the presence of $\mathrm{H}$ atoms on the Pt surface it is reasonable to expect hydrogenation of PA molecules. Such a reaction can be written as follows:

$\mathrm{CH} \equiv \mathrm{C}-\mathrm{CH}_{2} \mathrm{OH}+4(\mathrm{H}) \mathrm{Pt}=\mathrm{CH}_{3}-\mathrm{CH}_{2}-\mathrm{CH}_{2} \mathrm{OH}+4 \mathrm{Pt}$

and when the applied potential is located within the potential range of $\mathbf{H}$-atom electroadsorption, reaction ( $2 a$ ) is followed by the fast reaction

$\mathrm{Pt}+\mathrm{H}^{+}+\mathrm{e}^{-}=\mathrm{Pt}(\mathrm{H})$

Therefore, the occurrence of reaction (2b) obviously implies a cathodic current to replace the $\mathrm{H}$ adatoms consumed through reaction (2a). The extent of reactions (2a) and ( $2 b)$ depends on the value of the applied potential, i.e. on the degree of surface coverage by $\mathbf{H}$ atoms. Hydrogenation reactions involving ethylenic and acetylenic groups on Pt electrodes in acids are known for a series of organic molecules [9,10]. In this respect, it is well established that Pt behaves as a good electrocatalyst for hydrogenation reactions [11]. According to reaction (2b), propanol ( $\mathrm{PrOH})$ is the reaction product. This alcohol can be electro-oxidized on $\mathrm{Pt}$ in $0.5 \mathrm{M} \mathrm{H}_{2} \mathrm{SO}_{4}$ at potentials greater than $0.4 \mathrm{~V}[5,6]$. The slight increase in the voltammetric current (Fig. 2c) observed after chemical reaction between $\mathrm{H}$ atoms and PA (Fig. 2b) can be assigned to traces of $\mathrm{PrOH}$ produced at stage IV in the experiments described in Fig. 2a.

In the absence of H-atoms, the voltammetric electro-oxidation of the electroadsorbed residue becomes very similar to that found earlier for the electro-oxidation of adsorbates prepared on $\mathrm{Pt}$ in acid solution from other unsaturated, although rather simple, organic molecules such as ethylene [12] and acetylene [13]. In the case of PA, the origin of this type of adsorbate can be explained through disruptive electroadsorption of the molecule as expressed by the following reactions:

$$
\begin{aligned}
& \mathrm{CH} \equiv \mathrm{C}-\mathrm{CH}_{2} \mathrm{OH}+n \mathrm{Pt}=[\mathrm{CH}=\mathrm{C}-\mathrm{CHOH}] \mathrm{Pt}_{n}+\mathrm{H}^{+}+\mathrm{e}^{-} \\
& {[\mathrm{CH}=\mathrm{C}-\mathrm{CHOH}] \mathrm{Pt}_{n}=[\mathrm{CH}=\mathrm{CH}] \mathrm{Pt}_{n^{\prime}}+[\mathrm{CHO}] \mathrm{Pt}_{n^{\prime \prime}}}
\end{aligned}
$$

or

$[\mathrm{CH}=\mathrm{C}-\mathrm{CHOH}] \mathrm{Pt}_{n}=\left[\mathrm{CH}_{2}=\mathrm{CH}\right] \mathrm{Pt}_{n^{\prime}}+[\mathrm{CO}] \mathrm{Pt}_{n^{\prime \prime}}$

According to these reactions, the initial electroadsorbate (reaction 3 ) implies the formation of a single proton in the electroadsorption process. The results show that the maximum anodic charge density that can be assigned to this process is about 60 $\mu \mathrm{C} \mathrm{cm}{ }^{-2}$. If one compares this figure to the charge density of the $\mathrm{H}$-adatom monolayer on polycrystalline $\mathrm{Pt}$, which is $210 \mu \mathrm{C} \mathrm{cm}{ }^{-2}$ [14], one can assume that $n$, the number of sites per electroadsorbate species for reaction (3) should be close to 4 . Furthermore, the initial electroadsorbate is presumably disrupted into two different adsorbed residues through either one or both of the foreguing reactions (4a) and 
(4b). These reactions produce unsaturated and CO-containing adsorbates, probably involving two adsorption sites each, so that $n^{\prime}=n^{\prime \prime}=2$. The formation of ethylenic species, i.e. the most strongly bound residue, is consistent with the appearance of the main voltammetric electro-oxidation peak at about $1.0 \mathrm{~V}[12,13]$ entirely overlapping the O-electroadsorption current (Figs. 1d, 3c and 3d). The appearance of the CO-containing adsorbates can be related to the anodic current around $0.6-0.7 \mathrm{~V}$ observed in the voltammograms.

When going towards negative potential after adsorption at $E_{\text {ad }}=-0.100 \mathrm{~V}$, the ethylenic species is hydrogenated and partially desorbed, so that the hydrogen evolution current is increased. This is observed during the first few voltammetric sweeps. Correspondingly, as the ethylenic species accumulate on the surface, they give rise to an oxidation current at $0.6-0.7 \mathrm{~V}$, as seen in the voltammograms depicted in Fig. 3. The overall reaction occurring in the intermediate potential range, i.e. at potentials where the $\mathrm{Pt}$ surface is only partially covered by $\mathbf{H}$ atoms, turns out to be more complex because of the competition between the $\mathrm{H}$ atoms and the PA electroadsorption reactions taking place in the course of the chemical reaction between $\mathrm{PA}$ and $\mathrm{H}$ atoms. The bare $\mathrm{Pt}$ sites left by the latter reaction are competitively filled up through $\mathrm{H}^{+}$-ion discharge (reaction $2 \mathrm{~b}$ ) and PA electroadsorption (reaction 3). Therefore, one can definitely conclude the existence of competitive processes due to the interaction between PA and smooth Pt surfaces. Furthermore, one can also establish qualitatively that the PA electroadsorption reaction appears to be somewhat slower than the $\mathrm{H}^{+}$-ion discharge reaction itself, although the former reaction is much faster than the chemical reaction between PA and adsorbed $\mathrm{H}$ atoms.

(V) CONCLUSIONS

Different electroadsorption processes on smooth $\mathrm{Pt}$ in acid solution can be distinguished in the presence of propargyl alcohol. Thus, the electroadsorption of propargyl alcohol on bare smooth Pt can be interpreted as a deprotonation reaction followed by the rupture of the initial electroadsorbate yielding ethylenic and CO-containing adsorbed residues.

In the presence of $\mathrm{H}$ adatoms, electrochemical hydrogenation of PA is observed. Finally, under intermediate $\mathrm{H}$-adatom coverages, competitive electroadsorption reactions are found. In this case, after prolonged potential holding the Pt electrode becomes inactive for the $\mathrm{H}$-adatom electroadsorption reactions, although reactivation of the Pt electrode can be accomplished by potential cycling, but the time required for this treatment is longer when the most strongly bound adsorbates, i.e. those involving unsaturated bonds, are produced.

\section{ACKNOWLEDGEMENTS}

Financial support for this work by the Gobierno de Canarias (Dirección General de Universidades e Investigación) under Research Contract No. 46/01.06.88 is 
gratefully acknowledged. A.J.A. thanks the Faculty of the Universidad de La Laguna for the invitation to cooperate with the Departamento de Química Física during June-July 1988.

\section{REFERENCES}

1 I. Epelboin, M. Keddam and H. Takenouti, J. Appl. Electrochem., 2 (1972) 71.

2 M.A. Sánchez, J.J. Podestá and A.J. Arvia, An. Quím., 85 (1989) 8.

3 V.P. Kuidina, N.A. Zakarina and G.D. Zakumbaeva, Trans. Inst. Org. Katal. Elektrokhim. Akad. Nauk Kaz. SSR, 6 (1973) 114; G.D. Zakumbaeva, V.P. Kuidina and N.A. Zakarina, Zh. Fiz. Khim., 52 (1978) 1811.

4 R.S. Gonçalves, J.M. Léger and C. Lamy, Electrochim. Acta, 14 (1989) 473.

5 W. Vielstich in J.D.E. McIntyre, S. Srinivasan and F.G. Will (Eds.), Proc. Symp. Electrode Mater. Energy Conv., The Electrochemical Society, Princeton, NJ, 1977, p. 505.

6 R. Gonçalves, J.M. Léger and C. Lamy, Electrochim. Acta, 33 (1988) 1581; C.S. Fugivara, P.T.A. Sumodjo and T. Rabockai, ibid., 34 (1989) 363.

7 R. Woods in A.J. Bard (Ed.), Electroanalytical Chemistry, Vol. 9, Marcel Dekker, New York, 1976, p. 1.

8 A. Visintin, J.C. Canullo, W.E. Triaca and A.J. Arvia, J. Electroanal. Chem., 239 (1988) 67.

9 J.O'M. Bockris and S. Srinivasan, Fuel Cells: Their Electrochemistry, McGraw-Hill, New York, 1969.

$10 \mathrm{M}$. Fleischmann and D. Pletcher in N.S. Hush (Ed.), Reactions of Molecules at Electrodes, Wiley, New York, 1971, p. 347.

11 R. Dietz and H. Lund in M.M. Baizer (Ed.), Organic Electrochemistry. An Introduction and a Guide, Marcel Dekker, New York, 1973, Ch. 24, p. 829.

12 W.E. Triaca, T. Rabockai and A.J. Arvia, J. Electrochem. Soc., 126 (1979) 218.

13 A.B. Delgado, A.M. Castro Luna, W.E. Triaca and A.J. Arvia, J. Electrochem. Soc., 129 (1982) 1493.

14 T. Biegler, D.A.J. Rand and R. Wood, J. Electroanal. Chem., 29 (1971) 269. 